\title{
Carcinoma of the bronchus in the Yorkshire region of England 1976-1990: trends since 1984
}

\author{
C.K. Connolly*, S.M. Crawford**, P.L. Rider+, A.D.M. Smith+, \\ C.F. Johnston+, M.F. Muers++
}

Carcinoma of the bronchus in the Yorkshire region of England 1976-1990: trends since 1984. C.K. Connolly, S.M. Crawford, P.L. Rider, A.D.M. Smith, C.F. Johnston, M.F. Muers. CERS Journals Ltd 1997.

ABSTRACT: We wished to confirm that, in patients with lung cancer, trends in demography and histology, together with modest improvements in survival, first seen in the 1976-1983 cohorts, continued to 1990.

All lung cancer patients resident in Yorkshire are notified to the Cancer Registry, whose database was analysed for this report.

A total of 38,275 patients were notified. There was no change in annual notification for males but an increase from 513 to 815 annual notifications in females between 1976 and 1990. Mean age increased by $3 \mathrm{yrs}$, in males to $67.4 \mathrm{yrs}$ and in females to 67.2 yrs. Histological confirmation rate increased from $43 \%$ to $60 \%$ (mean age from 60.8 to $64.5 \mathrm{yrs}$ ). Annual notifications of adenocarcinoma increased consistently from 108 to 253 . Two year surgical survival improved from 37.4 to $44.3 \%$, doubling in subjects aged $\geq 70$ yrs to $43.8 \%$. Over the 15 year period, there was no improvement in survival aged $<60 \mathrm{yrs}$, but a significant improvement in the 60-69 and $\geq 70$ yrs age groups. Analysis of survival by quartiles showed significant improvement at all levels (first interval 20 to 24 days, median 79 to 91 days, third interval 224 to 266 days).

The modest improvement in outlook was confirmed, confined to older subjects after 1983, and partially masked by increasing age. Survival after surgery is now independent of age.

Eur Respir J 1997; 10: 397-403.

\begin{abstract}
*Friarage Hospital, Northallerton, North Yorkshire and Darlington Memorial Hospital, Co. Durham, UK. **Cancer Medicine Research Unit, University of Bradford, Bradford, West Yorkshire, UK. +Yorkshire Cancer Registry, Yorkshire Cancer Organisation, Leeds, West Yorkshire, UK. ++Regional Cardiothoracic Centre, Killingbeck Hospital, Leeds, West Yorkshire, UK.
\end{abstract}

Correspondence: C.K. Connolly Darlington Memorial Hospital

Hollyhurst Road

Darlington

Co. Durham DL3 6HX

UK

Keywords: Bronchial carcinoma Cancer Registry data

histological confirmation rates lung cancer

survival

Received: February 131996

Accepted after revision October 261996
Bronchial carcinoma is the commonest cause of cancer in males in the UK and its prevalence is increasing in females. It places a heavy burden on the health services, and in the last three decades the resources employed in its management have increased. In this study, we have attempted to provide evidence of an improvement in outlook following this increased deployment of resources. In the early 1970s and 1980s fibreoptic bronchoscopy had become widely available [1], and chemotherapy was established as first-line treatment for all patients with small cell lung cancer [2]. In our first attempt to assess the impact of these changes, we studied all patients diagnosed as having bronchial carcinoma in the Yorkshire Region of the National Health Service in England during the period 1976-1983 [3]. The survey was designed to detect any benefit in survival arising from the changes, and modest improvements were found.

Since 1983, the provision of fibreoptic bronchoscopy has increased further, so that it is virtually universally available, already covering $88 \%$ of the district general hospitals in the UK by 1987. Computed tomography (CT) scanning has become more accessible, and surgical and, in particular, anaesthetic techniques have advanced. There is now wide acceptance of chemotherapy as primary treatment for small cell carcinoma. It has been shown to extend life by about 6-12 months in the responders, who represent the majority of patients $[4$,
5]. We wished to see whether the trend to an improvement in outcome continued as the impact of the changes became more widespread. This paper presents the results of an extension of the survey for a further $7 \mathrm{yrs}$ up to 1990. It should be read in the light of the continued increase in the mean age at presentation of lung cancer, which was first reported by CogGon and ACHESON [6] and confirmed in our previous paper [3].

\section{Methods}

The Yorkshire Regional Cancer Registry records details of all subjects with cancer in the Yorkshire Region of the National Health Service. The population of the region at the time of the survey was 3.6 million. It was divided into 17 districts (population range 115,000$365,000)$. With one exception, each was served by a district general hospital, general services for one district being provided in a nearby town. The area includes industrial conurbations in West Yorkshire, the relatively isolated cities of Hull and York, and the large rural areas of North and East Yorkshire. Data are collected primarily by peripatetic registration officers, employed and trained by the Registry. They visit designated hospitals in the region to abstract clinical information from the case notes of cancer patients. All pathology laboratories in the region routinely send copies of histology reports 
of confirmed cancers. We studied all patients registered in the period 1984-1990, comparing them with those registered between 1976 and 1983. The database is continually updated. Information, not available when the previous paper was written, has been included and accounts for minor discrepancies with the results presented previously. Death certificate registrations (less than $5 \%$ of the total) were excluded, except for the calculations of incidence, as they could not contribute to the analysis of survival.

\section{Diagnosis}

Cases were subdivided histologically. The recorded diagnosis was confirmed by histological reports sent independently from the laboratories in the region, resulting in a virtually $100 \%$ return. The World Health Organization (WHO) classification was used. Unusual types of malignant lung tumours were included in the "other histologically determined" category but carcinoid was excluded. When discrepancies occurred between different specimens, the following hierarchy was used to determine the type: surgical or autopsy specimen, diagnostic histology, cytology. An increase in the number of patients with adenocarcinoma now allowed the recognition of five diagnostic categories: 1) squamous cell carcinoma, including large cell epidermoid tumours; 2) small cell carcinoma; 3) adenocarcinoma; 4) other histologically defined types, histologically or cytologically confirmed malignancy type not defined and 5) clinical diagnosis without histological or cytological confirmation.

\section{Treatment}

Four treatment categories were accepted: 1) surgery (with the intention of radical excision); 2) chemotherapy; 3) radiotherapy (radical or palliative to the primary); and 4) "no specific intervention", including nonradical surgery, hormone therapy and other palliative measures. "Active treatment" encompasses the first three categories.

All patients were put into a single diagnostic and a single treatment category. Patients who had multiple therapy were assigned to the treatment category that was the highest in the order above, so that, for example, surgery might include chemotherapy, radiotherapy or both, while chemotherapy might include radiotherapy but not surgery.

\section{Statistics}

Survival was calculated from the date when first seen in secondary care (or date of histological confirmation of the few patients managed entirely in primary care), the end-point being death from any cause.

Kaplan-Meier curves generated by the LIFETEST procedure, of the statistical package, Statistical Analysis System (SAS), were used for survival analysis of different subgroups. Relative survival was calculated from national life tables for each year from 1976. In groups where surgical intervention made an important contribution to management, 2 year survival is presented.

Cox proportional hazards regression was used to examine survival differences in the population as a whole.
The models included all those patients diagnosed during life between 1976 and 1990. The categories included: sex, age, treatment group, and histological diagnosis (squamous cell carcinoma, small cell carcinoma, adenocarcinoma, other confirmed, nonconfirmed). In these models, with the exception of patients with small cell cancer, chemotherapy and radiotherapy were combined. The age groups were: $<60,60-69$ and $\geq 70$ yrs; and the period under study was divided into three 5 year periods: $1976-1980,1981-1985$ and 1986-1990. Interactions amongst the explanatory variables were included in the statistical models, as well as the single differences between the principal categories. Statistical significance was calculated on the basis of overall difference between the survival curves.

\section{Results}

\section{General}

Registration. A total of 18,120 patients from the Yorkshire Region was registered before death between 1984 and 1990 (average 2,580 per year), and, as reported previously 20,155 (2,519 per year) between 1976 and 1983 . The numbers and ages of the subjects are summarized in table 1 . The incidence in males was little changed, but the increase in female notifications led to a decrease in the male/female ratio from 3.6:1 in 1976 to 2.8:1 in 1983 and 2.1:1 in 1990. The proportion of males aged under $60 \mathrm{yrs}$ fell from $22 \%$ in the first 5 year period to $15 \%$ in the second, and in females from $26 \%$ to $16 \%$; whilst the proportion over 70 yrs of age rose from $42 \%$ to $51 \%$ in males and from $40 \%$ to $49 \%$ in females. However, the pattern of change was different in the two sexes. In males, it was principally due to a disproportionate fall in the number of younger patients, whilst in females it was due to an absolute rise of the incidence of carcinoma in those over 60 yrs of age, particularly those aged over 70 yrs. This is illustrated in table 2, which shows the percentage change in the population at risk and absolute incidence of carcinoma between the first 5 year period (1976-1980) and the third (19861990). This resulted in a more rapid upward age drift in females $(64-67 \mathrm{yrs} ; \mathrm{p}<0.001)$ than in males $(65-67$ yrs: $\mathrm{p}<0.001)$.

Histological confirmation. The rate of histological confirmation continued to increase from $41 \%$ in 1976 to $62 \%$ in 1990 (fig. 1), but there were still considerable differences between districts in 1990, the range being $47-77 \%$. This improvement was partially masked by the continued upward drift in age at presentation. The proportion of histologically confirmed cases increased in

Table 1. - Number of patients registered and their mean age in each 3 year period between 1976 and 1990

\begin{tabular}{lllllc}
\hline \multirow{2}{*}{ Year } & \multicolumn{2}{c}{ Males } & & \multicolumn{2}{c}{ Females } \\
\cline { 2 - 3 } \cline { 5 - 6 } & $\mathrm{n}$ & $\begin{array}{l}\text { Age } \\
\text { yrs }\end{array}$ & & $\mathrm{n}$ & $\begin{array}{c}\text { Age } \\
\text { yrs }\end{array}$ \\
\hline $1976-1978$ & 6202 & 64.7 & & 1678 & 64.0 \\
$1979-1981$ & 6317 & 65.3 & & 1959 & 64.6 \\
$1982-1984$ & 6202 & 66.3 & & 2246 & 65.7 \\
$1985-1987$ & 5927 & 67.1 & & 2458 & 66.6 \\
$1988-1990$ & 5750 & 67.4 & & 2652 & 67.2 \\
\hline
\end{tabular}


Table 2. - Percentage change in population at risk and change in number with carcinoma bronchus from 1976-1980 to $1986-1990$

\begin{tabular}{|c|c|c|c|c|}
\hline \multirow[b]{2}{*}{$\begin{array}{l}\text { Age } \\
\text { yrs }\end{array}$} & \multicolumn{2}{|c|}{ Male } & \multicolumn{2}{|c|}{ Female } \\
\hline & $\%$ at risk & $\begin{array}{c}\% \text { carcinoma } \\
\text { bronchus }\end{array}$ & $\%$ at risk & $\begin{array}{c}\% \text { carcinoma } \\
\text { bronchus }\end{array}$ \\
\hline$<60$ & 0 & -39 & 0 & -14 \\
\hline $60-69$ & +2 & -14 & -4 & +54 \\
\hline$\geq 70$ & +13 & +9 & +8 & +80 \\
\hline
\end{tabular}

each three year period from 1976 in every age group (table 3). Over the whole period, the increase was $18 \%$ for all subjects. Stratification by age showed that the increase was over $20 \%$ in each group, except in those aged over 75 years, where histological confirmation rose by $20 \%$, to $39 \%$. The mean age at histological confirmation also increased from 60.8 (1976) to 63.5 (1983) and $64.5 \mathrm{yrs}$ in 1990 . The trend remained significant $(p<0.01)$. In the last 3 yrs, the rate of histological confirmation remained higher in males than females (males $61 \%$ and females $59 \% ; \mathrm{p}=0.01$ ). The ratio of small to squamous cell carcinoma was unaltered at about 3:7. The rate of increase in numbers of both of these types slowed between 1983 and 1990, but the absolute numbers known to have adenocarcinoma increased at an accelerated rate. Table 4 shows the proportion of histological types diagnosed during the last $3 \mathrm{yrs}$ of the study. The number of cases of adenocarcinoma had increased from 108 in 1976 to 153 in 1983, and 253 in 1990.

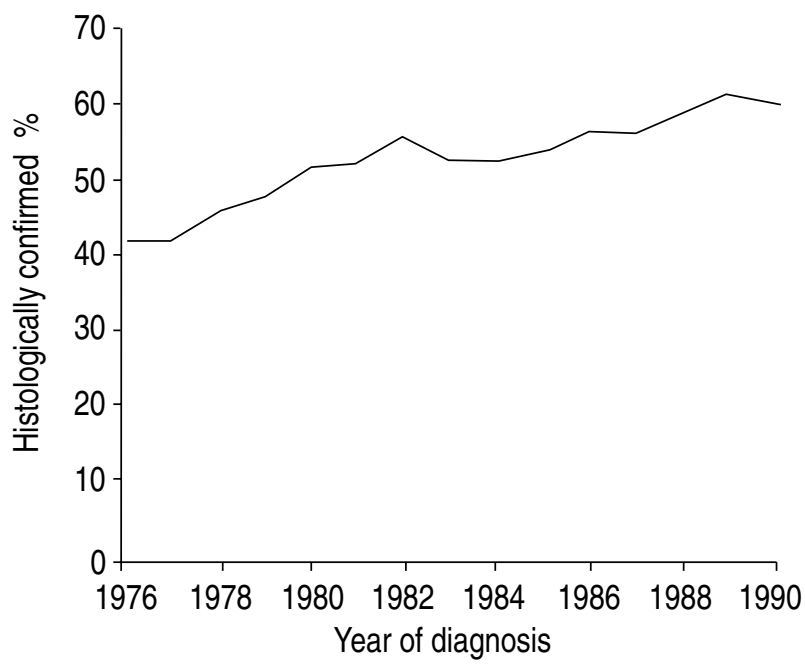

Fig. 1. - Overall histological confirmation rate from 1976 to 1990.

Table 3. - Histological confirmation rate by age group 1976-1990

\begin{tabular}{lccccc}
\hline & \multicolumn{5}{c}{ Histological confirmation $\%$} \\
Age group & $1976-$ & $1979-$ & $1982-$ & $1985-$ & $1988-$ \\
yrs & 1978 & 1981 & 1984 & 1987 & 1990 \\
\hline$<60$ & 61 & 68 & 73 & 77 & 82 \\
$60-64$ & 52 & 60 & 66 & 70 & 73 \\
$65-69$ & 46 & 55 & 61 & 63 & 69 \\
$70-74$ & 35 & 47 & 50 & 54 & 60 \\
$\geq 75$ & 19 & 26 & 31 & 32 & 39 \\
\hline All ages & 43 & 50 & 54 & 55 & 60 \\
\hline
\end{tabular}

Surgery. The numbers treated surgically fluctuated between 251 and 336 per year (9.7-11.9\% of all subjects). A fall in the number of patients in the younger age groups was balanced by a significant increase in the number of operations on those aged over $70 \mathrm{yrs}$. The operation rates had remained constant under the age of 70 yrs (<60 yrs 20\%; 60-64 yrs 15\%; 65-69 yrs 12.5\%), but had increased over the age of 70 yrs $(\mathrm{p}<0.01)(70$ 74 yrs from $8 \%$ to $9 \%(\mathrm{p}<0.01) ; \geq 75$ yrs from $1 \%$ to $3 \%(\mathrm{p}<0.01))$. In the earlier years, the prognosis for radical surgery was best under the age of 60 yrs. Survival is now almost independent of age, certainly after the somewhat high early mortality in older age groups is discounted (fig. 2). The two year survival rates are compared in table 5 , being approximately $44 \%$ in all age groups. This confirms that, with proper selection, good long-term results can be obtained in older patients. In the period 1986-1988, the two year survival after surgery over the age of 70 yrs was $44 \%(n=162)$, compared with $6 \%$ for this age group as a whole.

Overall active treatment. The overall rate of active treatment increased in all age groups (table 6), but, even in $1988-1990,80 \%$ of patients over the age of $75 \mathrm{yrs}$ did not receive specific therapy. The increases were principally due to increased proportions receiving chemotherapy in the younger patients, and surgery or radiotherapy in the older subjects.

\section{Specific management by diagnosis}

Squamous cell carcinoma. In 1990, the majority of patients with squamous cell carcinoma were still aged

Table 4. - The percentage of cases by histological type diagnosed during the period 1988-1990

\begin{tabular}{lcc}
\hline Type & $\begin{array}{c}\text { Females } \\
\%\end{array}$ & $\begin{array}{c}\text { Males } \\
\%\end{array}$ \\
\hline Squamous cell & 23 & 31 \\
Small cell & 14 & 11 \\
Adenocarcinoma & 10 & 7 \\
Other confirmed & 13 & 14 \\
Clinical & 39 & 38 \\
\hline
\end{tabular}

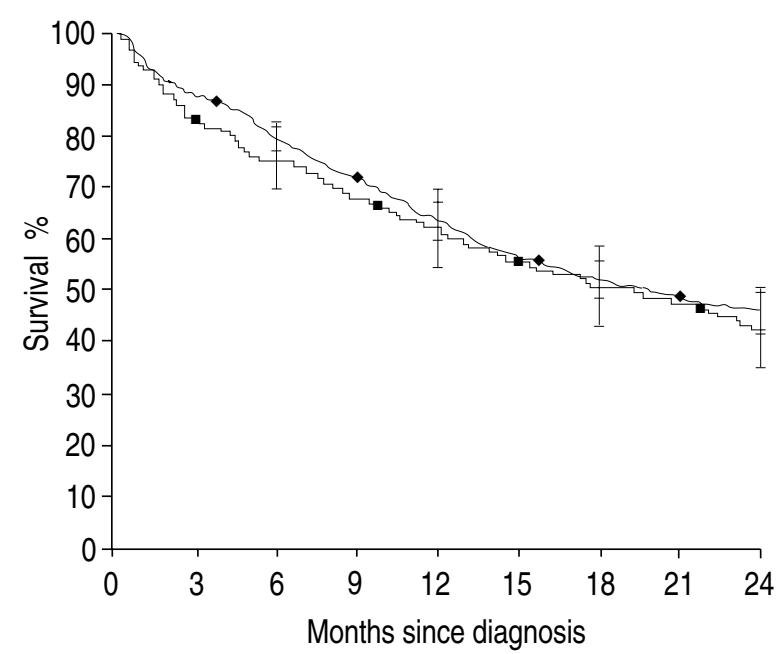

Fig. 2. - Survival curves after radical surgery by age group for those $<70$ yrs of age $(\longrightarrow)(n=696)$ and those $\geq 70$ yrs of age $(-)(n=161)$. Vertical bars are the $95 \%$ confidence interval. 
Table 5. - Two year survival rates for surgically treated cases

\begin{tabular}{lcc}
\hline $\begin{array}{l}\text { Age group } \\
\text { yrs }\end{array}$ & $\begin{array}{c}1976-1978 \\
\mathrm{n}(\%)\end{array}$ & $\begin{array}{c}1986-1988 \\
\mathrm{n}(\%)\end{array}$ \\
\hline$<60$ & $327(41)$ & $267(44)$ \\
$60-69$ & $390(38)$ & $436(44)$ \\
$\geq 70$ & $98(22)$ & $162(44)$ \\
\hline \multirow{2}{*}{ All } & $815(37)$ & $865(44)$ \\
\hline
\end{tabular}

less than 70 yrs. The management of these younger patients did not alter. However, the proportion of patients over the age of 70 yrs did increase, as did therapeutic activity in this age group. These two effects balance each other out, so there is no change in the overall active treatment rate for squamous cell carcinoma, which remained at over $60 \%$ during the whole period. The survival curves by modality of treatment are shown for patients presenting between 1986 and 1988. Surgery remained the only treatment associated with more than $10 \%$ survival at 2 yrs. Up to 18 months, radiotherapy, but not chemotherapy, was associated with significantly better survival than no active intervention (fig. 3). Despite the increased activity in the elderly, the apparent increase in survival of all patients over the age of 70 yrs was not significant (2 year survival $6 \%$ in 1976 , and $8 \%$ in $1987 ; \mathrm{p}=0.37$ ).

Adenocarcinoma. The numbers of patients diagnosed as having adenocarcinoma increased sufficiently during the second period to warrant separate analysis. The results in those patients treated surgically were very similar to squamous cell carcinoma. The survival of patients with inoperable adenocarcinoma was worse than for squamous cell carcinoma (1984-1988 nonsurgical cases: squamous cell carcinoma median survival 122 days, 2 year survival $6.5 \%$ (7.4-5.7), adenocarcinoma median survival 59 days, 2 year survival 5.9\% (7.7-4.1). The Cox model suggested a marginal advantage for females (risk ratio (RR) females 1.00 ; males $1.16(1.06-1.27)$ ).

Small cell carcinoma. The survival curves for all cases of small cell carcinoma for each 3 year period since 1977 are shown in figure 4 . The overall prognosis improved in a single incremental step at the time of the general introduction of chemotherapy in younger patients. This improvement has been maintained, despite subsequent increases in the age and proportion of those being treated (table 7). A later improvement in the outlook with chemotherapy for those over the age of 60

Table 6. - Percentage of cases receiving active treatment by age group 1976-1990

\begin{tabular}{lccccc}
\hline & \multicolumn{5}{c}{ Cases receiving active treatment }
\end{tabular}

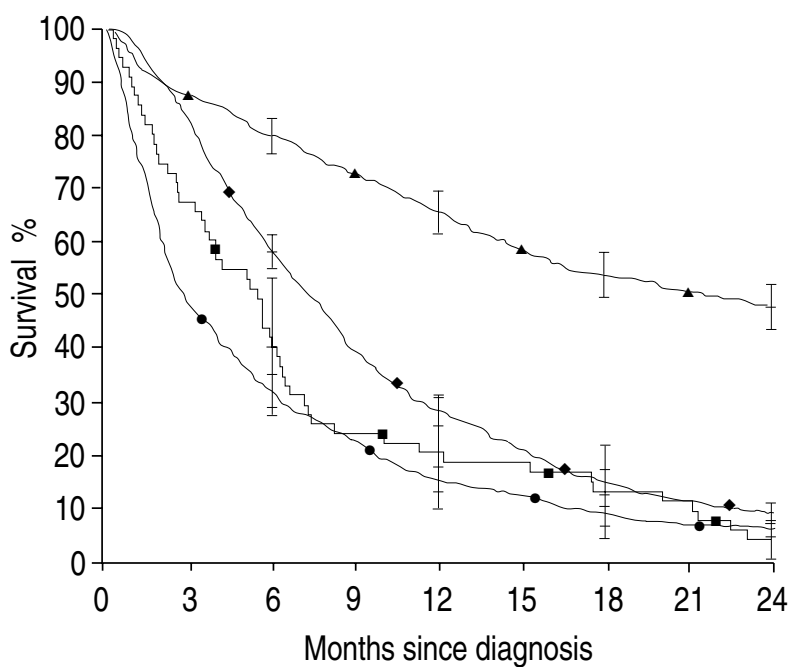

Fig. 3. - Survival of subjects with squamous cell carcinoma from 19861988 by treatment group. —— : chemotherapy $(\mathrm{n}=55)$; $\longrightarrow$ : radiotherapy $(\mathrm{n}=957) ; \square$ : radical surgery $(\mathrm{n}=535) ;-\square$ : no treatment $(\mathrm{n}=886)$. Vertical bars are the $95 \%$ confidence interval.

yrs, is concealed in the overall figures. Over the age of $70 \mathrm{yrs}$, this improvement in survival was seen at 6 months, but not at 1 year or thereafter. The good results for surgery in patients over the age of $70 \mathrm{yrs}$, which we reported previously, have not been confirmed. Nevertheless, radical surgery was still no less successful than in

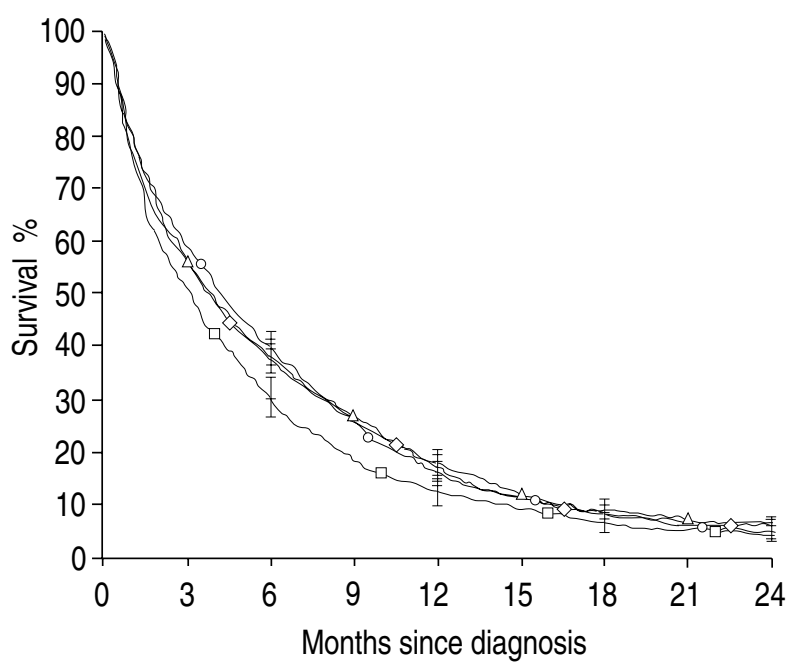

Fig. 4. - Overall survival in small cell carcinoma by three year periods from 1977-1979 to 1986-1988. —— : 1977-1979 ( $\mathrm{n}=653)$;

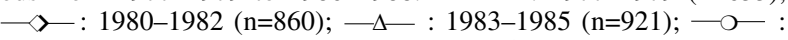
1986-1988 (n=973). Vertical bars are the $95 \%$ confidence interval.

Table 7. - Number (\%) of small cell cases treated by chemotherapy

\begin{tabular}{lcc}
\hline $\begin{array}{l}\text { Age group } \\
\text { yrs }\end{array}$ & $\begin{array}{c}1976-1978 \\
(\mathrm{n}=622)^{\#}\end{array}$ & $\begin{array}{c}1986-1988 \\
(\mathrm{n}=981)^{\#}\end{array}$ \\
\hline$<60$ & $53(21)$ & $154(66)$ \\
$60-64$ & $21(21)$ & $94(50)$ \\
$65-69$ & $21(18)$ & $96(44)$ \\
$70-74$ & $16(17)$ & $53(27)$ \\
$\geq 75$ & $5(10)$ & $21(15)$ \\
\hline All ages & $116(19)$ & $418(43)$ \\
\hline
\end{tabular}

\#: total number of small cells. 


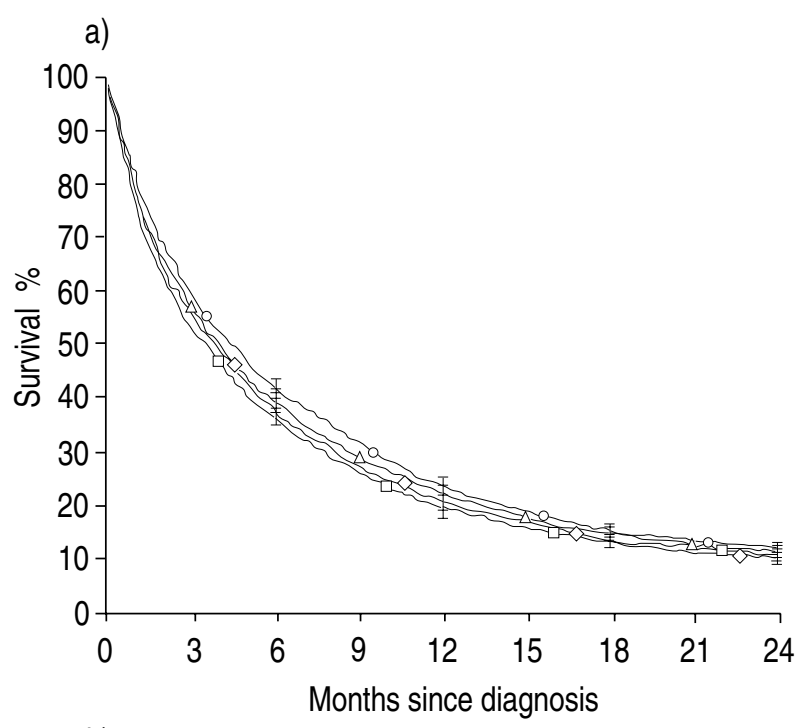

b)

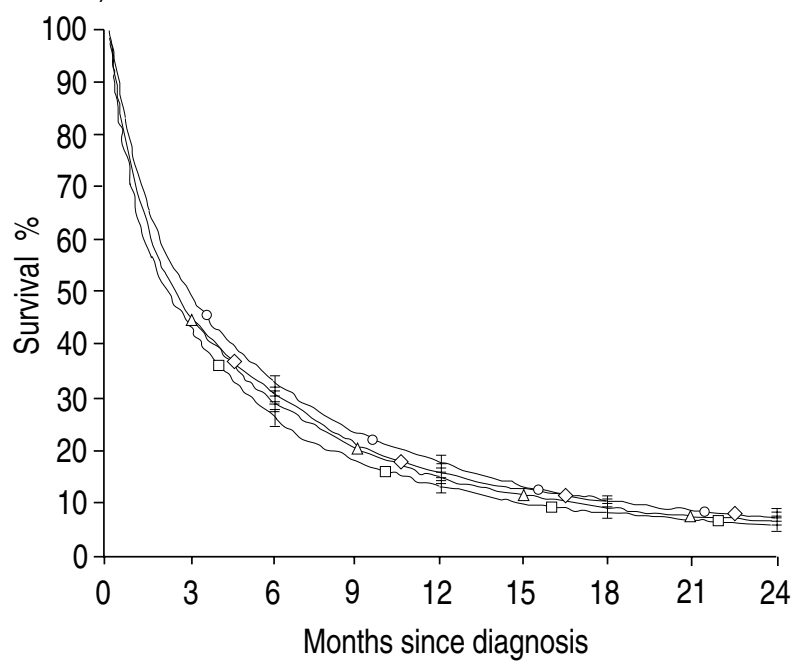

Fig. 5. - Survival to 2 yrs in each three year period for subjects aged: a) 60-69 yrs; and b) $\geq 70$ yrs. —- : 1977-1979 (a) $\mathrm{n}=2,887$; b) $n=3395) ; \longrightarrow$ : $\longrightarrow$ 1980-1982 (a) $\mathrm{n}=2,853$; b) $\mathrm{n}=3656$ ); $\longrightarrow-\Delta-$. 1983-1985 (a) $n=2,827$; b) $n=4140$ ); —- : 1986-1988 (a) $n=2,944$; b) $n=4252$ ). Vertical bars are the $95 \%$ confidence intervals.

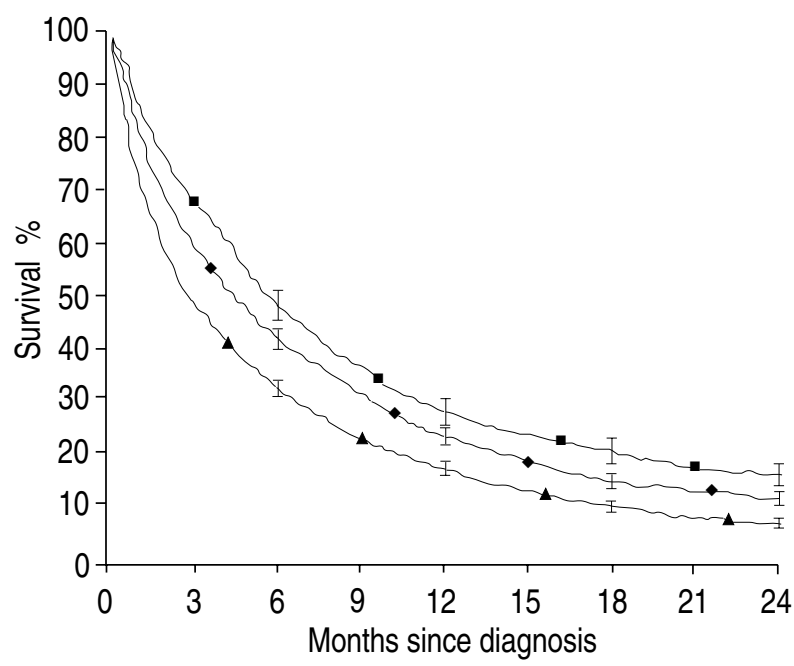

Fig. 6. - Overall survival by age from 1986-1988. —- : <60 yrs of age $(\mathrm{n}=1,262) ; \longrightarrow: 60-69$ yrs of age $(\mathrm{n}=2,944) ;-\boldsymbol{\Delta}-: \geq 70$ yrs of age $(n=4,252)$. Vertical bars are the $95 \%$ confidence interval.
Table 8. - Relative risks of death calculated from Cox model: period and treatment

\begin{tabular}{lccc}
\hline Period & Untreated & $\begin{array}{c}\text { Non-surgically } \\
\text { treated }\end{array}$ & $\begin{array}{c}\text { Surgically } \\
\text { treated }\end{array}$ \\
\hline $1976-1980$ & $1.00^{\#}$ & 0.51 & 0.22 \\
$1981-1985$ & 0.99 & 0.48 & 0.20 \\
$1986-1990$ & 0.96 & 0.47 & 0.17 \\
\hline
\end{tabular}

\#: base of comparison.

the other histological groups in those few patients under the age of 60 yrs in whom it was suitable (20 between 1984 and 1987). Two thirds of the diagnoses were made retrospectively from specimens taken at operation. Once again, overall survival of females was better than males (RR females 1.00; males 1.12 (1.05-1.19)).

Remaining subjects. The number of patients with other histological diagnoses did not justify detailed analysis. These and histologically nonconfirmed patients continued to have a poor prognosis. In the nonhistologically confirmed group, there were no differences in survival between males and females, and there was a slight worsening of outcome over the period. This is compatible with the previous suggestion that the majority of histologically nonconfirmed cases were indeed lung cancer, despite the absence of histological proof.

\section{Survival of the population as a whole}

The Cox model confirmed that there was a gradual improvement in survival over the period under study, with patients diagnosed between 1986 and 1990 having a somewhat better outcome. If the 2 year survival is considered, then there was no improvement over the period in survival of those under the age of $60 \mathrm{yrs}$. Survival curves for the 60-69 yrs and over 70 yrs age groups are shown in figure 5 . There is a small but consistent improvement in both age groups.

The Cox model also confirmed that there was a trend to poorer survival with age, which is illustrated for the last years of the study by the survival curves shown in figure 6.

The survival of patients given best supportive care changed little over the period under study, whereas there was a steady improvement in the survival of the surgically-treated group and an initial improvement in the non-surgically-treated group (between the periods 19761980 and 1981-1985), but little change thereafter (table 8 ). The net result of these changes was a significant increase in 2 year survival for the population as a whole, from $6 \%$ in 1976 to $9 \%$ in $1990(\mathrm{p}<0.04)$.

When analysed by quartiles, the proportionate increase in survival and its significance was greatest in those with the best potential for survival. Seventy five percent survival increased from about 20 to 24 days (annual percentage trend $0.7 \% ; \mathrm{p}<0.02)$, median survival from 79 to 91 days $(1.1 \%$ per year; $\mathrm{p}<0.01)$, and $25 \%$ survival from 224 to 266 days $(1.3 \%$ per year; $\mathrm{p}<0.001)$. If relative rather than crude survival is considered, the results are similar. 


\section{Discussion}

This study had a similar database to the previous one [3], and is, therefore, directly comparable but subject to the same advantages and limitations. The registry covers a clearly defined population, thus ensuring an accurate denominator for the population. Cases are unlikely to be missed because of the double notification system during life, backed up by automatic receipt of death certificates from the Office of Population Censuses and Surveys, the national registration body. This guarantees that virtually all cancers are recorded. On the other hand, the clinical data comes from several disparate sources with different management policies, and the laboratory data are subject only to national quality control. The WHO classification of histopathological typing of lung tumours is used generally in the region. The tumour/node/metastasis (TNM) status of the patients was not recorded. This does not compromise the epidemiological conclusions about overall survival or differences in survival between histological types. In this context, if available, it might be used as an explanatory variable in assessing the reasons for differences in outcome. Similarly, with regard to specific therapies, it might explain differences in outcome between different histological types, but its absence does not invalidate the conclusions. It would be of importance if the surgical outcome of patients of the same TNM status but of different histological types were different, but this is not within the scope of the study. This is an observational study and, therefore, reports the results of any change in policy that might have taken place over the period. It is not possible to determine what, if any, these have been. They are unlikely to have been great with surgery, though where a major change has taken place with regard to chemotherapy and small cell cancer, the expected improvements in outcome have been demonstrated.

The extension to the observation period makes it easier to demonstrate the significance of minor trends, and we were now able to confirm a consistent improvement, which was greater in, but not confined to, patients with a better outlook. Over the whole 15 year period, there was an upward trend in age, which is necessarily associated with diminished potential survival, whilst the increase in proportion of female subjects would have the opposite effect. The overall analysis with the Cox regression model confirmed that there was an improvement after making allowances for these changes. On the other hand, changes in the general health of the population and their effect on life expectancy are further potential confounders. To allow for these factors, relative as well as crude survival was analysed. The difference between these outcome measures was negligible, suggesting that the above confounders are not of importance in the present study. The major factors associated with the improvement in outlook appeared to be a progressive willingness to operate on older subjects throughout the period, and the introduction of chemotherapy for small cell carcinoma in the earlier years.

There was an increase in the histological confirmation rate from a low base. The survival of patients believed to have lung cancer, in whom the diagnosis was not histologically confirmed, was very poor but deteriorated only slightly during the period. These findings are compatible with the view that the majority of these patients did indeed have lung cancer diagnosed in the terminal stages. They also suggest that there was no major transference of good prognosis patients from the nonhistologically confirmed group to the specific histological categories, that would have introduced a bias in favour of improvement.

The increase in the histological confirmation rate and the demographic changes do mean that more older people have histologically confirmed cancer of all three principal types. There is no indication that the optimal intervention rate has yet been achieved in older subjects. The overall resection rate in this study is lower than in most other series, but many of these may be subject to error arising from too small a denominator because of incomplete registration or selection bias. The resection rate of just over $10 \%$ is in line with the national figures of the British Society of Thoracic Surgeons but half that seen in a recent study from Holland, where complete registration was obtained ensuring an accurate denominator [7]. In this study, the resection rate in patients under the age of 60 yrs was constant throughout, at $20 \%$, a similar rate to the proportion of the total population subjected to surgery in the Dutch study.

In our study, the outcome has been stable in patients under the age of $60 \mathrm{yrs}$, but there has been a consistent improvement in survival of older patients treated surgically, so that survival is now independent of age. This has occurred despite the increase in proportion of patients over the age of $70 \mathrm{yrs}$, who were subject to radical surgery. A detailed analysis of the favourable outcome in a group of these patients has been published elsewhere [8]. The improvement in outcome with more frequent intervention suggests that the optimal resection rate has not yet been reached in these subjects, and might possibly approach the $20 \%$ seen in patients under the age of $60 \mathrm{yrs}$ in the present study and overall in the Dutch population. Although numbers operated on between the ages of 70-74 yrs have indeed increased, even now very few patients aged 75 yrs and over are subject to operation. At present, there is no sign that policy is changing in this respect, but as the age of those presenting continues to rise and the fallacy of contraindication on the grounds of age is recognized, many more patients over the age of 75 yrs might be considered for operation, particularly if they are otherwise physically fit. Similarly, although there was no further improvement of the outcome for small cell carcinoma in patients less than $60 \mathrm{yrs}$ of age, there was an improvement not only in those aged over 60 yrs but also in those over 70 yrs of age, treated with chemotherapy. As patients may do well irrespective of age, and with surgery, selection on narrow grounds of chronological age is no longer justified. It is important that the outcome of older patients is carefully monitored. We anticipate that, if patients are properly assessed and management is appropriate, then the outcome of those who are reaching their eightieth year is likely to be little, if any, worse than those in their early seventies.

Although there are welcome improvements in the management and outcome of the elderly, these are relatively small, and the majority of patients still have a very poor prognosis. This raises the possibility that there may be limits to the benefits obtained from currently 
available therapy. If this is so, the optimal rate of investigation, particularly bronchoscopy, may not be $100 \%$. In attempting to assess optimal intervention rates, it should not be forgotten that confirmation of the diagnosis may have benefits in patient management (e.g. elimination of other diagnoses, prediction and therapy of complications) which would not necessarily be reflected in improved survival or greater frequency of specific anticancer treatment. Nevertheless, survival might give some indication of the appropriate level of intervention. The histological (including cytology) rate achieved in those under 60 yrs of age is now approaching $80 \%$. Prognosis in this group has not improved over recent years, so $80 \%$ might prove to be the optimal rate. This is lower than that achieved in other countries [9, $10]$, where the proportion of patients with a better prognosis may be higher, and so a higher intervention rate is justified. Bronchoscopy is well-tolerated in the elderly $[11,12]$, so that age should be no bar, and the target confirmation rate should, therefore, be independent of chronological age.

If this target of $80 \%$ for histological confirmation rate is indeed correct, there is at present a shortfall of 15$20 \%$ in histological confirmation for the region as a whole, and hence in surgical and other therapeutic intervention. This might contribute to the generally poor outcome of carcinoma of the bronchus in the UK compared with other European countries, as seen in the Eurocare study [13]. The analysis by district showed that there is considerable variation between the centres within Yorkshire, even after allowance for age differences. This might prove a fruitful field for prospective audit.

The current outcome for bronchial carcinoma, with a median survival of 91 days, and only $25 \%$ surviving to 260 days and $9.4 \%$ to 2 yrs, is still a very dismal prospect. With appropriate surgery and chemotherapy, we have demonstrated a small improvement in the elderly. The improvement with chemotherapy was confined to small cell carcinoma, but recent meta-analysis of the outcome of trials of chemotherapy in non-small cell carcinoma [14] has suggested that, provided platinum base regimens are used, there is potential for improved survival in these patients. Furthermore, the discussion above only considers survival, and the possibility that quality of life might be improved independently of survival by more appropriate management after a full assessment has not been addressed. Nevertheless, the improvements demonstrated here are small, and not likely to increase exponentially in the future; hence, primary prevention aimed at reducing risk factors, principally by discouraging cigarette smoking, remains of paramount importance.

In conclusion, this study has shown a further modest improvement in the prognosis of some patients with bronchial carcinoma. This has been due mainly to improvement in the outcome for those patients in the seventh and eighth decades, who are actively managed. Increase in intervention parallels the increase in histological diagnosis, so that for each specific diagnosis the intervention rates have increased less. The increase in average age has masked some of the improvement, so there appears to be little overall benefit. Survival after surgery is now independent of age. In contrast to the previous study, there was no further improvement in the overall outcome for small cell carcinoma. Nevertheless, there was some further improvement in survival of older patients with small cell carcinoma treated by chemotherapy, and a definite improvement in the surgical outcome for older patients with non-small cell carcinoma.

These findings illustrate the importance of making histological diagnosis so that appropriate treatment can be pursued. Differences between age groups and districts suggests that the optimal level of histological confirmation has not yet been reached in the Yorkshire Region.

\section{References}

1. Simpson FG, Arnold AG, Purvis A, Belfield PW, Muers MF, Cooke NJ. Postal survey of bronchoscopic practice by physicians in the United Kingdom. Thorax 1986; 41: 311-317.

2. Anon. Cytotoxic chemotherapy before and after radiotherapy compared with radiotherapy followed by chemotherapy in the treatment of small cell carcinoma of the bronchus: the results up to 36 months. Br J Cancer 1983; 48; 755-761.

3. Connolly CK, Jones WG, Thorogood J, Head C, Muers MF. Investigation, treatment and prognosis of bronchial carcinoma in the Yorkshire Region of England 19761983. Br J Cancer 1990; 61: 579-583.

4. Bunn PA Jr, Cohen MH, Ihde DC, Fossieck BE Jr, Matthews MJ, Minna JD. Advances in small cell bronchogenic carcinoma. Cancer Treatment Reports 1977; 61: 333-342.

5. Klasa RJ, Murray N, Coldman AJ. Dose intensity metaanalysis of chemotherapy regimens in small cell carcinoma of the lung. J Clin Oncol 1991; 9: 499-508.

6. Coggon DA, Acheson ED. Trends in lung cancer mortality. Thorax 1983; 38: 721-723.

7. Damhuis RAM, Schuette PR. Resection rates and postoperative mortality in 7,899 patients with lung cancer. Eur Respir J 1996; 9: 7-10.

8. Gebitekin C, Gupta NK, Martin PG, Saunders NR, Walker DR. Long-term results in the elderly following pulmonary resection for non-small cell lung carcinoma. Eur $J$ Cardiothorac Surg 1993; 7: 653-656.

9. Beard CM, Jedd MB, Woolner LB, Richardson RL, Bergstrahl EJ, Melton LJ III. Fifty year trend in incidence rates of bronchogenic carcinoma by cell type in Olmstead County, Minnesota. J Natl Cancer Inst 1988; 80: 1404-1407.

10. Frolund C, Krasnick M, Rosenstock S, Storm HH. Lungekraeft i Danmark 1943-1986. Ungesker Laeger 1990; 152: 1241-1245.

11. Knox AJ, Mascie-Taylor BH, Page RL. Fibreoptic bronchoscopy in the elderly: 4 years experience. $\mathrm{Br} \mathrm{J}$ Dis Chest 1988; 82: 290-293.

12. Macfarlane JT, Storr A, Ward MY, Roderick-Smith WH. Safety, usefulness and acceptability of fibreoptic bronchoscopy in the elderly. Age Ageing 1981; 10: 127-131.

13. Eds: Berrino F, Sant M, Verdecchia A, Capocaccia R, Hakulinen T, Esteve J. Survival of Cancer Patients in Europe. The Eurocare Study. IARC Scientific Publications No. 1321995.

14. Non-Small Cell Lung Cancer Collaborative Group. Chemotherapy in non-small cell lung cancer: a meta-analysis using updated data on individual patients from 52 randomised clinical trials. BMJ 1995; 7010 (311): 899-909. 